\title{
Regulación del financiamiento participativo financiero —crowdfunding — en el Perú: ¿Estamos cometiendo el error de siempre? ${ }^{(*)}$
}

Adrian Tovar Ayllón

Abogado por la Universidad de Lima. Miembro Asociado de ADV Editores - Revista ADVOCATUS.

SUMARIO:

I. Introducción.

1. Crowdfunding como solución al problema de acceso al financiamiento.

2. Modalidades de Crowdfunding.

3. Situación de la regulación en el Perú.

II. ¿Es realmente necesario regular el Crowdfunding financiero?

III. ¿Cómo hacer una regulación que sume y no reste?

IV. Requisitos para el funcionamiento de sociedades administradoras.

1. Exigencias vinculadas a la situación financiera de las Sociedades Administradoras.

2. Clasificación de los Receptores por parte de las Sociedades Administradoras.

V. Límites de recaudación a receptores.

VI. Conclusiones.

(*) Nota del Editor: a la fecha de publicación del presente artículo, ya se ha publicado el Reglamento de la Actividad de Financiamiento Participativo Financiero y sus Sociedades Administradoras, Resolución SMV 045-2021-SMV/02, por lo que todas las opiniones vertidas en este artículo se basan en el Proyecto de Reglamento y reflejan la visión del autor antes de la emisión de la norma final. 


\section{RESUMEN:}

A través de este artículo, el autor realiza una crítica al Proyecto de Reglamento de la Ley de Crowdfunding. El autor parte de la premisa de que, si bien no es estrictamente necesario aprobar regulación especial para que esta actividad pueda desarrollarse con éxito, una adecuada regulación puede coadyuvar a su desarrollo al conseguir fortalecer la confianza del público inversionista en los Receptores y las Sociedades Administradoras que participan en el mercado. Sin embargo, llega a la conclusión de que el Proyecto de Reglamento padece de lo que etiqueta como "el error de siempre", es decir, se trata de una regulación excesiva que busca la protección del inversionista en detrimento del desarrollo y crecimiento de la actividad regulada. El autor finaliza haciendo un llamado a aprobar una normativa flexible y que confíe más en el funcionamiento del mercado.

Palabras clave: Crowdfunding, fintech, receptores, sociedades administradoras, regulación, MYPES, financiamiento.

\footnotetext{
ABSTRACT:

In this article, the author makes a criticism of the Crowdfunding Law Regulation Project. The author starts from the premise that, although it is not strictly necessary to approve special regulations for this activity to be carried out successfully, adequate regulation can contribute to its development by strengthening the trust of the investing public in the Recipients and Management Companies participating in the market. However, he arrives at the conclusion that the Draft Regulation suffers from what it labels as a "common mistake", that is, it is an excessive regulation that seeks to protect the investor to the detriment of the development and growth of the regulated activity. The author ends by calling for the approval of flexible regulations and greater trust in the functioning of the market.

Keywords: Crowdfunding, fintech, receivers, management companies, regulation, MYPES, financing.
}

\section{INTRODUCCIÓN}

\section{Crowdfunding como solución al proble- ma de acceso al financiamiento.}

Para todo empresario, grande o pequeño, la obtención de financiamiento suele ser un dolor de cabeza. Pero, lógicamente, más lo es para el pequeño empresario, ya sea que busque iniciar un emprendimiento $u$ obtener financiamiento para hacer crecer su negocio. No solo en el Perú, sino en todas partes del mundo, el acceso de los pequeños empresarios a fuentes de financiamiento es más limitado por su mayor nivel de riesgo. Fuentes tradicionales de financiamiento como bancos y demás entidades financieras pueden llegar a cobrar intereses muy altos o solicitar garantías que el empresario no está en capacidad de dar. Aquellos que tienen proyectos innovadores y apelan a atraer firmas de capital de riesgo - venture capital-o inversionistas ángeles enfrentan una durísima competencia para obtener su apoyo. Algunos gobiernos apoyan a través de programas pero su alcance es limitado. Al no lograr obtener financiamiento de estas fuentes, a muchos no les queda más que recurrir a amigos y familiares, pero difícilmente logran obtener volúmenes de financiamiento suficientes para cumplir sus objetivos.

El problema no es la ausencia de recursos en la economía para satisfacer la demanda por financiamiento, sino la concentración del poder de decisión sobre el manejo de esos recursos en pocas manos. Si la totalidad de mi financiamiento va a provenir de una única fuente, es natural que esa persona o entidad sea mucho más cuidadosa y exigente en su análisis para otorgar el financiamiento. Quizás concluya que soy demasiado riesgoso y desista de otorgarlo o lo haga bajo condiciones muy desfavorables. Pero, ¿qué sucede si ese riesgo es compartido por decenas o hasta cientos de personas? ¿Qué sucedería si surgieran maneras de canalizar los recursos que se encuentran dispersos en la economía hacia el financiamiento de los emprendedores y pequeños empresarios?

El público en general tiene una gran cantidad de recursos infrautilizados, ya sean bienes, espacios físicos, espacios virtuales, medios de transporte, recurso humano, capital, etc. El problema es que estos potenciales ofertantes no encuentran a los demandantes de tales recursos. Frente a esto, han surgido en los últimos 
años plataformas virtuales cuyo giro de negocio consiste justamente en proveer un canal para poner en contacto a ofertantes y demandantes de bienes y servicios. Estas tecnologías disruptivas están invadiendo variedad de mercados, como el de transporte, alojamiento o delivery; y tienen una enorme escalabilidad y capacidad para brindar un uso más eficiente al recurso del que se trate. ¿Por qué el acceso a financiamiento no puede tener una solución similar?

Desde hace ya varios años operan en el mundo plataformas virtuales que, aprovechando la tecnología, ponen en contacto a personas que buscan financiar alguna actividad con el público en general, quienes entregan fondos bajo una serie de modalidades. Esta actividad es lo que se conoce como Crowdfunding.

\section{Modalidades de Crowdfunding}

Se habla de modalidades de Crowdfunding pues el traspaso de recursos del público al solicitante de los mismos se puede hacer bajo diferentes figuras legales. Las cuatro modalidades básicas de Crowdfunding son las siguientes: (i) basado en donaciones, donde los usuarios hacen donaciones a un proyecto o causa sin recibir nada material a cambio, (ii) basado en recompensas, donde los usuarios hacen contribuciones a cambio de recompensas, que usualmente incluyen pero no se limitan a recibir el producto cuya producción ha sido financiada - funciona como una especie de preventa-, (iii) basado en préstamos —-también llamado Crowdlending - , donde los usuarios realizan pequeños préstamos directamente a personas o empresas que buscan financiamiento a cambio de la devolución de su dinero, generalmente, con intereses, y (iv) basado en valores, donde los usuarios invierten en una empresa a cambio de recibir valores emitidos por ésta, —usualmente acciones representativas del capital, por lo cual también se le suele llamar Equity Crowdfunding-.

No existe mucha información actualizada de pú- blico acceso sobre los volúmenes de dinero que se maneja en el mercado de Crowdfunding bajo todas sus modalidades, sin embargo, uno de los estudios más citados es aquel realizado por Massolution ${ }^{1}$-2015-, del cual podemos extraer algunas conclusiones bastante ilustrativas sobre cómo se ha venido desenvolviendo el mercado. Lo primero que se debe resaltar de este estudio es que arrojaba un crecimiento anual promedio a nivel mundial, del año 2013 al 2014, de tres cifras - 167\%-, que me atrevería a decir se debe haber mantenido, al menos, por algunos años. En segundo lugar, el estudio demostró que la modalidad de Crowdfunding que moviliza el mayor volumen de recursos es la basada en préstamos, y por mucho margen sobre el resto. Ello probablemente se debe a que es una modalidad que genera rentabilidad a los usuarios - a diferencia de la basada en donaciones y recompensas- pero que es más simple que aquella basada en valores - por lo tanto más atractiva para un mayor número de compañías-, además de funcionar tanto para personas naturales como jurídicas. Sin perjuicio de ello, la modalidad con la que se recaudaron mayor cantidad de fondos por campaña fue la basada en valores, lo cual guarda sentido con las finalidades que se persiguen en esta clase de campañas, la mismas que son más demandantes de recursos.

\section{Situación de la regulación en el Perú.}

Antes de que se aprobara regulación alguna, ya existían algunas plataformas en Perú que ofrecían servicios bajo la modalidad de préstamos. Al no constituir intermediación financiera, estas empresas no se encontraban infringiendo ninguna ley mediante la prestación de sus servicios sin autorización previa de alguna entidad estatal. Distinta era la situación de la modalidad basada en valores. En el Perú, hasta ahora, no existen plataformas que trabajen bajo esta modalidad pues la emisión pública de valores está sujeta a altas exigencias y aprobaciones regulatorias, lo cual hace totalmente inviable su desarrollo.

1. Massolution, "The Crowdfunding Industry Report", 2015CF (2015), http://reports.crowdsourcing.org/index. php?route=product/product\&product_id $=54$ 
Viendo las ventajas que las modalidades financieras del Crowdfunding podría traer, en particular, para el financiamiento de emprendimientos de alto impacto ${ }^{2}$ y las micro y pequeñas empresas - MYPES-, así como los riesgos que estas actividades podrían traer para el público en general de continuar operando sin regulación, diversos organismos públicos - Ministerio de Economía, Superintendencia del Mercado de Valores y Superintendencia de Banca, Seguros y AFP-y personas del sector privado empezaron a impulsar el desarrollo de una ley al respecto. Finalmente, se concretó una regulación plasmada en el Título IV del Decreto de Urgencia 013-20203 en adelante, la "Ley de Crowdfunding"-. Asimismo, mientras este artículo se encontraba en proceso, la Superintendencia del Mercado de Valores publicó un proyecto para reglamentar la Ley de Crowdfunding, el mismo que fue puesto a disposición del público para comentarios desde el 29 de noviembre de 2020 -el "Proyecto de Reglamento"-

El propósito del presente artículo es evaluar la necesidad de regular o no el Crowdfunding financiero en el Perú y, de ser afirmativa la respuesta, explorar la mejor manera de hacerlo, usando como objeto de comentario tanto la Ley de Crowdfunding como el Proyecto de Reglamento.

\section{II. ¿ES REALMENTE NECESARIO REGULAR EL CROWDFUNDING FINANCIERO?}

Sin perjuicio de que a la fecha ya contamos con nuestra propia Ley de Crowdfunding e inclusive un Proyecto de Reglamento, considero que vale la pena hacer el ejercicio de reflexionar sobre si existía realmente una necesidad de regular el Crowdfunding financiero. Entiéndase por "regular" algo mucho más complejo que simplemente exceptuar una $u$ otra modalidad de alguna regulación existente - como claramente era necesario en el caso de la modalidad basada en valores-. A lo que me refiero con "regular" es a la creación de un marco normativo específico que establezca las reglas de juego aplicables a las personas que se dediquen a realizar actividades de Crowdfunding -esto involucra el procedimiento para el otorgamiento de autorizaciones, establecimiento de obligaciones, prohibiciones, etc.-. Pero antes de responder esta interrogante, quisiera retroceder un paso y responder una pregunta algo más amplia para luego avanzar al caso particular: ¿cuándo es necesario, en general, regular una actividad económica?

En términos generales, considero necesario regular una actividad si, al menos, se presentan todas las siguientes condiciones:

a) Se trata de una actividad de una relevancia y alcance tal que involucra un interés público que necesita ser protegido.

b) Las personas cuyos intereses se buscan proteger están en una posición de desventaja frente a los demás agentes involucrados en la actividad y no es razonable asumir que los primeros estarán en capacidad de superar esa desventaja por sus propios medios, ya sea individual o colectivamente, por lo que es necesaria supervisión estatal para compensar esa disparidad.

c) Existen motivos razonables para creer que las personas que participan en dicha actividad no serán capaces de actuar en armonía con el interés público - existe peligro de un actuar fraudulento-. Ello es el caso, por ejemplo, si se observa que no existe una debida alineación de intereses.

¿Cumple el Crowdfunding con estas condiciones? Opino que la respuesta a esta pregunta es sumamente debatible, especialmente en lo que

2. El término "emprendimiento de alto impacto" se suele emplear para referirse a aquellos emprendimientos caracterizados, entre otros, por tener un componente innovador y ser escalables - es decir, que tienen una capacidad de rápido crecimiento-.

3. Decreto de Urgencia 013-2020, http://spij.minjus.gob.pe. 
respecta al numeral (iii) anterior. Ahora, analicemos cada condición en orden.

Sería muy difícil negar que la condición descrita en el numeral (i) no se cumple. Conceptualmente, el Crowdfunding busca financiar actividades apelando a fondos del público en general valiéndose de un medio masivo de comunicación como el Internet y, en la práctica, no hablamos de poco dinero. Las cifras arrojadas por Massolution eran altísimas en cuanto al volumen de dinero canalizado a través de plataformas de Crowdfunding -USD 16.2 billones en 2014-. Además, se trata de una industria que está lejos de llegar a su pico. Como toda fintech, una plataforma de Crowdfunding constituye un negocio de gran escalabilidad, lo cual se refleja en un crecimiento anual muy alto. En vista de los hechos, sí considero que el Crowdfunding es una actividad que involucra un interés público.

La condición (ii) puede generar algo más de debate pues no es algo que se pueda demostrar propiamente con cifras, pero al final creo que sí es posible considerar como cumplida, al menos parcialmente. El público en general, obviamente, está compuesto por personas que pueden o no tener experiencia en inversiones o conocimientos sobre cómo se maneja una empresa, sus etapas de desarrollo, sobre cómo leer su información financiera, etc. Asimismo, la gran mayoría de inversionistas no estarán en posición de negociar con los empresarios que buscan financiamiento el acceso a más información de la compañía de la que se hace pública para efectos de la campaña de recaudación de fondos, es decir, existe asimetría informativa. En ese sentido, creo que sí es posible hablar de una posición de desventaja de los inversionistas frente a las empresas o personas que buscan financiamiento tanto desde el punto de vista de conocimientos como de acceso a información —siendo más relevante este último punto-.
Respecto del asunto sobre la disparidad en cuanto a conocimientos, quiero hacer la salvedad de que es un tema más relativo de lo que parece a primera vista, y por esa razón considero que la condición materia de análisis se cumple solo parcialmente. No podemos cometer el error de visualizar al colectivo de inversionistas como un conjunto de personas ignorantes que usarán irresponsablemente su dinero y que, por lo tanto, necesitan de la intervención estatal para su propia protección. Primero, porque si estamos tratando con personas que tienen un excedente de dinero para invertir, es lógico suponer que se trata de personas con cierto nivel de estudios o de experiencia en alguna actividad económica. En ese sentido, son lo suficientemente capaces para responsabilizarse por el uso que le dan a su dinero. Y segundo, hay que considerar que, bajo determinadas circunstancias, un colectivo puede ser sumamente eficiente para resolver problemas o tomar decisiones - incluso más que un individuo experto- debido a la sumatoria de esfuerzos y la gran variedad de conocimientos que se pueden organizar y compartir con ayuda de las herramientas tecnológicas actuales. Algunos autores emplean el término "sabiduría de las masas" para referirse a este fenómeno, que considero se aplica perfectamente al contexto de una campaña de Crowdfunding. ${ }^{4}$ De hecho, se han producido varios casos donde los propios inversionistas han descubierto y puesto fin a intentos de fraude en diversas plataformas. Aunque no es objeto del presente artículo profundizar sobre este punto, es importante considerar esto al evaluar la "necesidad" de regular el Crowdfunding.

Siguiendo con el análisis de las condiciones, llegamos al numeral (iii); en mi opinión, el más debatible de los tres. Para el análisis, debemos comenzar identificando los incentivos que tienen las partes involucradas - sin considerar a los inversionistas, pues justamente es su interés el que se buscaría proteger con la regula-

4. Se recomienda la lectura de The Wisdom of the Crowd por J. Surowiecki y de Crowdsourcing; Why the Power of the Crowd is Driving the Future of Business, por J. Howe, para profundizar en este tema. 
ción-, es decir, por un lado, los empresarios que buscan financiamiento para sus proyectos -a quienes llamaré en adelante, para usar la nomenclatura de la Ley de Crowdfunding, "Receptores" $-y$, por el otro, las empresas que administran las plataformas virtuales que ponen en contacto a Receptores e inversionistas -en adelante "Sociedades Administradoras" -

Los Receptores tienen como objetivo obtener el financiamiento. Para ello deben convencer al público que el negocio que buscan financiar está en capacidad, ya sea de repagar el préstamo - si hablamos de Crowdlending - o de generar rentabilidad en el futuro - si hablamos de la modalidad basada en valores-. Para convencer al público deben ser capaces de generar la suficiente confianza, para lo cual tienen que, al menos, identificarse plenamente y exponer sus cualificaciones. En esa línea, mal haría un grupo de personas que tiene por objetivo defraudar a quienes los financian elegir una campaña de Crowdfunding como medio, pues se expondrían públicamente. Estarían obligados a crear un esquema complejo que resista el escrutinio de decenas o cientos de personas que podrían descubrir falsedades en lo declarado y exponerlos antes de siquiera completar la campaña.

Y no nos tenemos que quedar en el plano teórico para verificar que el fraude es un fenómeno inusual en el mundo del Crowdfunding. Admito que no hay aún muchos estudios sobre la habitualidad del fraude en campañas de Crowdfunding. Sin embargo, los estudios que se encuentran a disposición son congruentes al concluir que el fraude es sumamente raro. Por ejemplo, Cumming y Johan ${ }^{5}$-2020 - tras estudiar cientos de campañas de las plataformas Kickstarter e Indiegogo en diversos países concluyeron que el nivel de fraude era inferior que aquel que se encuentra en la Bolsa de Valores de Nueva York y en Nasdaq. Asimismo, en un trabajo anterior, Cumming, Hornuf, Karami y Schwaizer ${ }^{6}$-2016-, con miras al desarrollo de modelos que permitan prevenir e identificar el fraude en campañas de Crowdfunding, identificaron patrones claros que permitían diferenciar campañas legítimas de campañas fraudulentas - siendo uno de esos patrones la no identificación de los Receptores a través de fotos o videos, y la ausencia de información sobre ellos en redes sociales-. Cabe recalcar que estos estudios se hicieron tomando como base plataformas de Crowdfunding bajo el modelo de recompensas; es decir, aquellas sobre las cuales, incluso al día de hoy, no existe regulación alguna.

En el campo del Crowdfunding financiero, la propia Securities Exchange Commission - $\mathrm{SEC}^{7}$ -2019-, regulador del mercado de valores de Estados Unidos, emitió un informe que debía evaluar los resultados de la regulación aprobada en 2016 — JOBs Act-. De acuerdo al informe, en los primeros 3 años de aplicación de la norma, la SEC no tuvo a su cargo ningún caso de fraude en el marco de Crowdfunding financiero, existiendo únicamente casos aislados a nivel de ciertos estados en los cuales no se concretó el financiamiento. Si bien este es un resultado post regulación, no creo que se pueda atribuir únicamente a ella, pues lo que se observa es un reflejo de lo que venía sucediendo antes de que la regulación exista. Desde luego, tampoco se puede negar que la regulación podría haber contribuido a mantener los bajos niveles de fraude que ya se tenían.

Además de ser una terrible idea usar una plataforma de Crowdfunding para cometer fraude, los Receptores tienen incentivos para hacer su

5. Douglas Cumming \& Sofia Johan, Crowdfunding: Fundamental Cases, Facts and Insights, (Cambridge, Massachusetts: Academic Press, 2019).

6. Cumming, J.,Hornuf, L., Karami, M. y Schweizer, D., "Disentangling Crowdfunding from Fraudfunding", Max Planck Institute for Innovation \& Competition Research, Paper no 16-09 (2020), https://ssrn.com/abstract=2828919

7. "Report to the Commission: Regulation Crowdfunding", en Securities Exchange Commission, acceso el 18 de junio de 2021, https://www.sec.gov/smallbusiness/exemptofferings/regcrowdfunding/2019Report 
mejor esfuerzo para lograr los objetivos prometidos a sus inversionistas, es decir, para evitar ser incompetentes. Los Receptores ponen su carrera y su reputación en juego al momento que lanzan sus campañas para recaudar fondos del público, y cualquier conflicto con los inversionistas, ya sea por incumplimiento de los compromisos asumidos, difusión de información falsa, omisión de información relevante o fracaso de la compañía por cualquier causa, puede tener una seria repercusión en su vida profesional y futuros proyectos. De más está explicar la gran capacidad que tienen el día de hoy las redes sociales para destruir reputaciones.

En resumen, si bien teóricamente los inversionistas pueden verse perjudicados ya sea por fraudes o Receptores incompetentes, el carácter público de una campaña, y, en general, la dinámica particular que tienen las campañas de Crowdfunding, generan desincentivos para que se presenten ambos escenarios. $Y$ no estoy diciendo que el Crowdfunding esté libre de fraude. El fraude existe inclusive en mercados altamente regulados. Lo que quiero resaltar es que, contrario a lo que se podría intuir, el Crowdfunding es un sector que no es proclive al fraude y ello debe considerarse al momento de plantearse la pregunta de regularlo o no.

En cuanto a las Sociedades Administradoras, como toda compañía, su finalidad es ganar dinero. Lo usual es que éstas cobren una comisión por cada campaña exitosa por una suma equivalente, en promedio, a $5 \%$ del monto recaudado por cada campaña. ${ }^{8}$ Esta es su principal fuente de ingreso, sin perjuicio de la posibilidad de cobrar otras comisiones por servicios adicionales. Claramente, el éxito de la Sociedad Administradora depende directamente de la capacidad de los proyectos publicados en su plataforma de atraer inversiones del público. Esto significa que el activo más importante de la Sociedad Administradora es, finalmente, la confianza, algo muy difícil de construir y fácil de perder por culpa de proyectos de mala calidad o algún caso de frau- de, siendo irrelevante si la Sociedad Administradora tuvo o no responsabilidad por lo sucedido.

Dicho lo anterior, creo que una Sociedad Administradora, independientemente de que la ley la obligue o no, está obligada por las propias circunstancias del mercado, si quiere mantenerse en el tiempo y ser competitiva, a tomar todas las medidas que estén a su alcance para trabajar únicamente con Receptores que, a su juicio, tienen las mejores probabilidades de cumplir los compromisos asumidos con sus inversionistas y que, obviamente, no representan un riesgo de fraude. Como se explicará más adelante, muchas Sociedades Administradoras implementan procesos de debida diligencia para filtrar qué Receptores ingresan en sus plataformas, aunque no exista regulación que las obligue. Este es un factor muy relevante para explicar los bajos niveles de fraude en el mercado.

Del breve análisis que se ha realizado de cada condición, considero posible justificar el cumplimiento de las condiciones (i) y (ii) —esta última, de manera parcial- . Sin embargo, respecto de la condición (iii), no considero que existan razones suficientes para suponer que, ante la ausencia de regulación, se generaría un desborde de situaciones fraudulentas generadas por Sociedades Administradoras y Receptores inescrupulosos que se aprovechan de los inversionistas. Existe una alineación de intereses que minimiza la posibilidad que eso ocurra. Por este motivo, a la pregunta ¿es necesario regular el Crowdfunding financiero?, mi respuesta es que no. No veo al Crowdfunding desregulado convirtiéndose en un problema serio. Sin embargo, queda una pregunta más que responder: ¿es conveniente regular el Crowdfunding financiero?

Es importante entender la diferencia entre la necesidad de regular algo y la conveniencia de hacerlo. La necesidad de regular surge en la medida que su ausencia pueda generar un alto riesgo de daño a los intereses del público en general o impedir que la actividad se pueda 
desarrollar en absoluto. En el caso del Crowdfunding, el hecho de que sostenga que no es necesario regularlo, no significa que no podría ser conveniente hacerlo de determinada manera. La regulación puede ser algo deseable en la medida que coadyuve al desarrollo y mejore el desempeño de este sector. La gran interrogante es si ello es posible y cómo lograrlo.

\section{III. ¿CÓMO HACER UNA REGULACIÓN QUE SUME Y NO RESTE?}

Postular que el marco regulatorio de determinada actividad debe contribuir a su desarrollo en lugar de frenarlo es una propuesta a todas luces razonable. Por supuesto, ninguna entidad reguladora del mundo dirá abiertamente que es su intención aprobar normas legales perjudiciales para el desarrollo del sector objeto de regulación, aunque en la práctica, y generalmente con buenas intenciones, eso sea lo que consiguen. El problema es que los funcionarios públicos, por su condición como tales, tienen un sesgo del que difícilmente pueden desprenderse, y es que su primera prioridad no es promover el desarrollo de la actividad regulada, sino la protección de las personas que identifican están en posición de desventaja y de su propia posición como funcionarios públicos. No es mi intención sugerir que los funcionarios públicos no actúen en base a una vocación de servir al interés público, pero creo que hay que ser realistas y admitir que existe una relación entre la aprobación de regulaciones muy conservadoras y el temor que tienen estos funcionarios a que se les atribuya responsabilidad si algo malo sucede. Los funcionarios necesitan una regulación aprobada de la cual se puedan valer para defender su posición; a más restrictiva es mejor para ellos pues minimizan su propia responsabilidad.

En Norteamérica, Europa y Latinoamérica no parece haber país que no tenga desarrollada o en proceso de desarrollo regulación para el Crowdfunding financiero. En líneas generales, creo que todas las regulaciones buscan de alguna u otra manera establecer mecanismos de control y supervisión para proteger a los inversionistas. La gran diferencia entre unas y otras es el balance costo/beneficio que logran.
La principal, y quizás la única, razón que creo puede justificar establecer una regulación para el Crowdfunding financiero es para incrementar la confianza del público en esta actividad. En otras palabras, si bien no es necesaria la regulación por los motivos expuestos anteriormente, la regulación puede resultar conveniente siempre que el beneficio que genere en términos de confianza del público en los Receptores y Sociedades Administradoras - que debe traducirse en mayor participación y volumen de financiamiento- supere los costos asociados impuestos a éstos. Si esto sucede nos encontraremos ante una regulación correctamente balanceada y que aporta al desarrollo del sector regulado. Por el contrario, si la regulación está llena de mecanismos proteccionistas cuyo cumplimiento desincentiva la creación de Sociedades Administradoras o el uso del Crowdfunding financiero como alternativa de financiamiento por los Receptores, estaremos ante una regulación desbalanceada que termina frenando el desarrollo del sector.

De una lectura conjunta de la Ley de Crowdfunding y el Proyecto de Reglamento concluyo que no se está llegando al balance necesario para promover que el sector se desarrolle. Estas normas están demasiado orientadas hacia la protección del inversionista, estableciendo para ello un esquema regulatorio muy exigente e inflexible. Es el objetivo de las siguientes secciones tratar algunos de los temas más preocupantes de la regulación propuesta y plantear alternativas de mejora.

\section{REQUISITOS PARA EL FUNCIONAMIENTO DE SOCIEDADES ADMINISTRADORAS}

Sin Sociedades Administradoras no habrá Crowdfunding financiero. Esta obviedad parece haber sido pasada por alto por la Superintendencia del Mercado de Valores - SMV. El Proyecto de Reglamento ha optado por imponer altas barreras de entrada al mercado a través de exigentes requisitos para la obtención de las autorizaciones correspondientes, así como alta carga regulatoria a través de una serie de obligaciones permanentes, que no considero justificadas tomando en cuenta la naturaleza del negocio que persiguen realizar estas entidades. No es mi intención 
identificar todas las normas contenidas en la Ley de Crowdfunding o el Proyecto de Reglamento que se podrían ajustar al respecto, sino centrarme en unas pocas que considero pueden marcar la diferencia.

\section{Exigencias vinculadas a la situación fi- nanciera de las Sociedades Administra- doras.}

Entre los requisitos más exigentes del Proyecto de Reglamento encontramos la necesidad de contar con un capital social mínimo equivalente a la suma de $S / 400,000.00$ para iniciar operaciones. En un intento de flexibilizar este requisito, se permite que el $40 \%$ del capital mínimo esté cubierto por una carta fianza bancaria. Asimismo, el patrimonio neto de la Sociedad Administradora en ningún momento puede ser inferior a dicho monto, con excepción de los primeros 12 meses de operaciones, donde el patrimonio neto puede ser equivalente al $70 \%$ de aquel.

Asimismo, el Proyecto de Reglamento exige a las Sociedades Administradoras proporcionar sus estados financieros no auditados e información complementaria correspondiente al cierre de cada mes dentro de los 30 días siguientes, y sus estados financieros auditados como máximo el 28 de febrero de cada año. En lo que respecta a información eventual, las Sociedades Administradoras deben comunicar a la SMV dentro del día siguiente cualquier "hecho relevante" que pueda afectar el desarrollo de su actividad. El Anexo 4 del Proyecto de Reglamento contiene un listado no taxativo de hechos que califican como tal.

Lo que observamos en la normativa propuesta es el típico molde de las entidades supervisadas por la SMV, tales como sociedades agentes de bolsa o sociedades administradoras de fondos. El problema es que las Sociedades Administradoras de plataformas de Crowdfunding financiero tienen un negocio muy diferente al de estas entidades. El negocio de una Sociedad Administradora de plataformas de Crowdfunding es poner en contacto a Receptores e inversionistas. La Sociedad Administradora no es más que un canal que facilita la interacción entre estos dos grupos y no tiene ninguna capacidad de decisión respecto de las inversiones de sus clientes como sí lo tienen las sociedades agentes de bolsa y sociedades administradoras de fondos. Entonces, ¿por qué es necesario ser tan exigentes con las finanzas de las Sociedades Administradoras y mantenerlas bajo constante monitoreo?

Normalmente, la justificación para establecer requisitos de capital mínimo y de patrimonio neto es garantizar la solvencia de la entidad regulada de tal manera que pueda hacer frente a sus obligaciones y responsabilidades frente a sus clientes. Esto tiene sentido en la medida que la entidad supervisada, por la naturaleza del servicio que brinda, este en riesgo de incurrir en dicha responsabilidad. Y esto está directamente relacionado con el hecho de que la entidad supervisada maneje o no fondos del público - de manera discrecional o no-. En esa línea, considero que la raíz del problema se encuentra en el hecho de que la regulación parte de la premisa de que las Sociedades Administradoras van a custodiar directamente los fondos de los inversionistas mientras las campañas están en curso; ello a pesar de que la propia norma prevé algunos supuestos en que las Sociedades Administradoras pueden minimizar el contacto con tales fondos valiéndose de terceros - como entidades fiduciarias-?

9. El artículo 31 del Proyecto de Reglamento establece las formas en que las Sociedades Administradoras pueden manejar los fondos de los inversionistas: La Sociedad Administradora puede utilizar: "(...) (1) Cuentas bancarias abiertas en una entidad supervisada por la SBS. La Sociedad Administradora debe asegurar que dichas cuentas permitan la identificación de los Receptores e Inversionistas. Para la identificación de tales cuentas ante la entidad bancaria, la Sociedad Administradora debe presentar una declaración jurada donde manifieste que la cuenta será utilizada exclusivamente para canalizar fondos de los Receptores o Inversionistas y, que la cuenta es intangible según lo dispuesto en la Décima Quinta Disposición Complementaria Final del Decreto de Urgencia. (2) Fideicomiso administrado por entidades supervisadas por la SBS y autorizadas a actuar como fiduciarios, en el que la Sociedad Administradora actúa como fideicomitente. Son beneficiarios del fideicomiso los Inversionistas que hayan realizado abonos en las cuentas del fideicomiso y cuenten 
Otras jurisdicciones han seguido un camino opuesto, prohibiendo que las Sociedades Administradoras manejen directamente fondos del público — salvo que obtengan autorizaciones adicionales -.$^{10}$ La ventaja que encuentro a ello es que la considerable reducción del riesgo en cabeza de las Sociedades Administradoras puede justificar una menor carga regulatoria. Sin embargo, el Proyecto de Reglamento no hace ninguna distinción entre aquellas Sociedades Administradoras que manejan fondos del público de aquellas que implementan mecanismos para hacerlo por intermedio de terceros, y ésta es una de las principales oportunidades de mejora que encuentro para la legislación peruana de Crowdfunding financiero.

Si las Sociedades Administradoras acreditan ante la SMV que el dinero de los inversionistas se encuentra seguro, por ejemplo, en manos de una entidad fiduciaria debidamente supervisa$\mathrm{da}$, ¿qué sentido tiene exigirle una capital y patrimonio neto mínimo de $S / 400,000.00$ ? ¿Qué sentido tiene obligarlas a reportar sus estados financieros todos los meses - obligación equivalente a la que tienen las Sociedades Agentes de Bolsa-?

Diferenciar entre Sociedades Administradoras que custodian directamente los fondos de los inversionistas y aquellas que se valen de otros mecanismos más seguros no solo es importante para incentivar que las Sociedades Administradoras terminen inclinándose por lo segundo -lo cual resulta más beneficioso para los inversionistas que cualquiera de las obligaciones que contiene hoy el Proyecto de Reglamento- - Si observamos otros países, lo que termina sucediendo después es que surgen servicios especializados dirigidos a Sociedades Administradoras que les permite reducir los costos relacionados al manejo de los fondos. Por nombrar un ejemplo, en Estados Unidos existe una compañía bajo el nombre comercial de Crowdpay cuyo objeto es brindar servicios de pago mediante el uso de cuentas escrow para que los inversionistas puedan financiar, específicamente, campañas de Crowdfunding sin que la Sociedad Administradora tenga que tener contacto alguno con los fondos. Como esta compañía han surgido varias en Estados Unidos y Europa, demostrando que si se permite que el sector crezca, irán entrando al mercado compañías especializadas que brindarán servicios a las Sociedades Administradoras que les permitirá ser más eficientes y abaratar costos. Finalmente, cabe precisar que la norma no debería contener un listado taxativo de qué mecanismos se pueden emplear. Las Sociedades Administradoras deberían poder proponer otros mecanismos al regulador para su aprobación y así acceder a un régimen con menor carga regulatoria.

Poniendo de lado el tema de la necesaria diferenciación entre Sociedades Administradoras que manejan dinero del público y las que no, la regulación propuesta también carece de flexibilidad y de proporcionalidad, pues no hay relación entre el volumen de las operaciones de la Sociedad Administradora y los requisitos que debe cumplir. Tal y como está la propuesta, el capital mínimo y patrimonio neto mínimo es

con un saldo a su favor disponible en dichas cuentas. Las entidades que formen parte del mismo grupo económico de la Sociedad Administradora no podrán actuar como fiduciarios del fideicomiso. (3) Cuentas de dinero electrónico emitidas por empresas autorizadas en el marco de la Ley $N^{\circ} 29985$, Ley que regula las características básicas del dinero electrónico como instrumento de inclusión financiera, y su reglamento. (...)" - el subrayado es nuestro-.

10. En Estados Unidos, por ejemplo, las reglas 303(e)(1) y 303(e)(2) de Regulation Crowdfunding establecen que solamente las entidades que califican como broker dealers - el equivalente a una Sociedad Agente de Bolsa en el Perú- pueden realizar actividad de Crowdfunding financiero recibiendo dinero del público. Aquellas entidades que solamente funcionan como Sociedades Administradoras - denominadas Funding Portals-, no pueden hacerlo, pero están sujetos a una regulación mucho menos exigente que un broker dealer. Otro ejemplo lo encontramos en la legislación española, donde el artículo 52 de la Ley de Fomento de la Financiación Empresarial prohíbe que las Sociedades Administradoras reciban fondos del público salvo que cuenten, adicionalmente, con una autorización como entidad de pago híbrida. 
el mismo para todas las Sociedades Administradoras independientemente del volumen de sus operaciones. Y no solo es el mismo monto, sino que el monto es elevado desde el inicio. Los requisitos patrimoniales del Proyecto de Reglamento no dan cabida a la entrada al mercado de Sociedades Administradoras más pequeñas, lo cual, si queremos ver algún desarrollo del sector, no es algo que nos podamos dar el lujo de menospreciar.

Me da la impresión de que la idea detrás de las elevadas exigencias patrimoniales es, nuevamente, la protección de los inversionistas basado en el prejuicio de que las compañías pequeñas no serán tan profesionales y "seguras" para los inversionistas como las más grandes. El problema es que terminaremos teniendo un sector con muy pocas Sociedades Administradoras, probablemente de propiedad de los grupos económicos que ya encontramos hoy día en el sector financiero, y con poca competencia. Además, no olvidemos que las Sociedades Administradoras son fintechs, y como tal, tienen negocios de gran escalabilidad. En ese sentido, una compañía que comienza con poco capital y bajo volumen de operaciones, puede en poco tiempo despegar. Lo que se necesita es darles la oportunidad de acceder al mercado, y eso no está siendo promovido por la normativa que se propone.

Ahora bien, ¿cómo es posible flexibilizar los requisitos para operar como Sociedad Administradora sin dejar desprotegidos a los inversionistas? Creo que es perfectamente posible ello si establecemos requisitos proporcionales al volumen de las operaciones de cada Sociedad Administradora. Una solución que he observado en la legislación comparada - e.g. Españaes la posibilidad de optar por un seguro de responsabilidad civil en lugar de cumplir con un capital mínimo. La ventaja del seguro es que el costo del mismo va a depender de la evaluación que haga la aseguradora del nivel de riesgo de cada Sociedad Administradora, lo cual significa que el costo sería proporcional al riesgo, siendo un factor muy relevante para determinar ello el volumen de las operaciones de cada compañía y qué procesos internos tiene para administrar sus riesgos. En esa línea, el uso del seguro in- centivaría a que la propia compañía idee mecanismos para minimizar su riesgo y conseguir abaratar el seguro, por ejemplo, valiéndose de terceros para el manejo de los fondos recaudados en las campañas.

Otra alternativa podría ser establecer un capital mínimo escalonado que deba ajustarse de acuerdo al volumen de operaciones de cada Sociedad Administradora, estableciendo como piso, por obvias razones, un monto más bajo que el propuesto en el Proyecto de Reglamento. Esta alternativa me parece una opción mejor a la contenida el día de hoy en el Proyecto de Reglamento pues reduciría las barreras de entrada al mercado, lo cual puede incentivar el registro de más Sociedades Administradoras y una mayor competencia en el sector.

\section{Clasificación de los Receptores por parte de las Sociedades Administradoras.}

Como se ha explicado anteriormente, el negocio principal de las Sociedades Administradoras es poner en contacto a Receptores e inversionistas. Sin perjuicio de ello, es usual que éstas presten una serie de servicios adicionales que las pueden diferenciar unas de otras. El Proyecto de Reglamento, en su artículo 25, ha establecido una serie de servicios obligatorios que, si bien en su mayoría recogen lo que normalmente una Sociedad Administradora diligente haría, también contienen algunas que van más allá de lo que la práctica de mercado había venido demostrando.

Considero que es un problema cuando el regulador empieza a entrometerse demasiado en el negocio de las entidades que supervisa. Si bien es necesario establecer pautas de qué se puede y qué no se puede hacer, no hay que llegar al extremo de armarle el modelo de negocio a las Sociedades Administradoras en una norma legal. Este tema es especialmente delicado si se está regulando fintechs, pues la innovación requiere de un marco regulatorio flexible. En esa línea, una de las exigencias que más me preocupa es la contenida en el numeral 24.3 de la Ley de Crowdfunding y desarrollada en el numeral 25.4 del Proyecto de Reglamento:

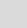


"24.3 Identificar y clasificar los riesgos de los receptores y de los proyectos de financiamiento participativo financiero. Las Sociedades Administradoras establecen libremente las metodologías a aplicar para el cumplimiento de dicho fin, a partir de criterios y de los niveles de riesgo que la SMV establece, los cuales son de público conocimiento."

"25.4 Efectuar la clasificación que permita clasificar a los Receptores y Proyectos de acuerdo al nivel de riesgo que implican para los inversionistas; así como analizar e identificar cualquier otra variable que resulte útil para que éstos tomen sus decisiones de inversión. Con dicho fin la Sociedad Administradora debe contar con una metodología de inversión para clasificar a los Receptores y Proyectos de acuerdo con el nivel de riesgo que implica para los inversionistas (...)"

Esta exigencia es una completa novedad por parte de la SMV. Habiendo revisado las legislaciones de países donde el sector fintech está mucho más desarrollado que el peruano, tales como Estados Unidos, Reino Unido o España, e inclusive países de la región como México o Colombia, no he logrado encontrar una exigencia similar. Estos países no solamente no requieren a la Sociedades Administradoras clasificar el riesgo de los proyectos, sino que ni siquiera las obligan a realizar algún nivel mínimo de revisión de información sobre los proyectos - lo que se conoce como due diligence-. Lo más exigente que he logrado observar es la obligación de, por motivos de transparencia, revelar si es que se hace o no se hace un due diligence y, en caso afirmativo, explicar en qué consiste éste.

Por ello me sorprendió encontrar este requerimiento en la Ley de Crowdfunding y el Pro- yecto de Reglamento. Más allá de salirse de lo que es el estándar regulatorio, considero que los perjuicios que puede ocasionar esta obligación superan ampliamente cualquier beneficio que se haya estimado. Los perjuicios a los que me refiero vienen en dos presentaciones: (i) sobrecostos y (ii) responsabilidad civil.

Evidentemente, para poder clasificar el riesgo de cualquier empresa es necesario revisar información de la compañía a cierto nivel de profundidad, es decir, hacer due diligence. De manera que la regla bajo comentario obliga a las Sociedades Administradoras a destinar recursos a realizar este estudio y además a otorgar una clasificación como resultado de dicho estudio. Claramente esto obliga a la Sociedad Administradora a contratar especialistas y destinar horas hombre a la labor, lo cual genera un costo adicional que disminuye el atractivo de constituir Sociedades Administradoras.

Además, las Sociedades Administradoras no son tan "libres" de fijar los criterios de sus metodologías. Aunque la Ley de Crowdfunding diga expresamente que sí tienen esa libertad, a renglón seguido dice que dicha libertad se ejerce "a partir de criterios y de los niveles de riesgo que la SMV establece (...)". En consecuencia, quien finalmente establece el estándar de las metodologías es la SMV y no las Sociedades Administradoras. El Proyecto de Reglamento no entró a describir de manera muy detallada y rígida los criterios pero sí establece algunos parámetros mínimos ${ }^{11}$, cuyo cumplimiento, satisfactorio o no, queda a criterio de la SMV. Queda pendiente que se defina si el incumplimiento de tales parámetros mínimos se traduce en la comisión de alguna infracción administrativa - pero seguramente será el caso-.

11. El numeral 25.4 del Proyecto de Reglamento establece que las metodologías para clasificar a Receptores y Proyectos deben tomar en cuenta lo siguiente: "(1) La metodología adoptada debe considerar como mínimo información relevante del Proyecto relacionada con su sector, industria y localización, utilizando criterios de evaluación homogéneos y no discriminatorios. (2) En los casos de Proyectos de préstamos se debe evaluar como mínimo la solvencia económica del Receptor, mediante el uso de herramientas cualitativas y cuantitativas. Para la solvencia económica se analizará como mínimo el historial crediticio, capacidad de pago e ingresos esperados del Receptor. Las Sociedades Administradoras que realicen dich a modalidad, deben ser usuarias de al menos una sociedad de información crediti- 
El costo adicional creado por la normativa no me generaría un problema en la medida que pudiera ver un claro beneficio para el sector. Pero lo cierto es que no logro ver de qué manera exactamente se beneficiará a los inversionistas. En el papel, suena muy bien establecer que todos los proyectos estarán clasificados por nivel de riesgo pues eso ayudará a los inversionistas a elegir solo los mejores proyectos o a manejar mejor el riesgo de sus inversiones. El problema es que, por definición, las compañías que usarán el Crowdfunding como fuente de financiamiento son compañías que involucran un mediano o alto riesgo. Entonces, no podemos asumir que por el solo hecho de colocarlo en una norma los resultados de las clasificaciones constituirán información realmente relevante para el análisis del inversionista pues, más allá de lo sofisticada que puede ser la metodología de la Sociedad Administradora, nada puede asegurar que la clasificación sea precisa.

Admito que no es igual analizar esta regla desde la perspectiva del Receptor que quiere solicitar un préstamo o emitir un valor representativo de deuda y aquel que planea emitir valores representativos de capital. En el primer caso, lo relevante es analizar la capacidad de pago, de manera que es más fácil y quizás hasta automatizable hacer la clasificación de riesgo. A las Sociedades Administradoras especializadas en esta modalidad, quizás esta normativa no les resulte tan perjudicial. Pero para el caso de la emisión de valores representativos de capital, el nivel de análisis que se requiere de la compañía Receptora para emitir una clasificación como pide la norma es mucho mayor y la probabilidad de equivocarse es más alta — con lo cual el potencial "beneficio" se vuelve aún más relativo-. En ese sentido, creo que esta exigencia termina siendo un desincentivo en especial para las Sociedades Administradoras especializadas en la modalidad de emisión de valores.

El segundo problema es que, al obligar a las Sociedades Administradoras a emitir una clasificación de riesgo, la normativa las expone a potenciales demandas por responsabilidad civil - ya sean fundadas o no- por parte de inversionistas que aleguen haber actuado confiando en dicha clasificación y se consideren perjudicados si el proyecto objeto de clasificación fracasó. Ello sin perjuicio de la interposición de denuncias administrativas que pueden desembocar en multas u otras sanciones. Estarían siendo expuestas a esto pese a que su negocio principal era, en principio, poner en contacto a Receptores e inversionistas y no clasificar el riesgo de proyectos; pero la norma las obligaría a ir más allá de su objeto principal. Si bien es cierto que, en ausencia de dolo, una Sociedad Administradora que sigue estrictamente sus metodologías debería ser capaz de evitar que se le impute responsabilidad civil, ello no la salvará de enfrentar potenciales procesos judiciales al respecto o hasta procesos administrativos si es que la SMV —o eventualmente INDECOPI - se atribuyen competencia suficiente para conocer de casos en donde la clasificación otorgada sea controvertida.

El problema de la responsabilidad incrementada no afecta a las Sociedades Administradoras solamente si se materializa, también puede generar dificultades por el solo hecho de que exista dicha posibilidad. Anteriormente, se sugirió, por ejemplo, que una alternativa para reducir la carga regulatoria de las Sociedades Administradoras era permitirles contratar seguros de responsabilidad civil en lugar de cumplir con un capital mínimo. Como es obvio, el costo de la prima es mayor entre más expuesta esté la So-

cia y utilizar dicha información como componente de su metodología de evaluación de Proyectos. (3) Para Proyectos de valores se debe analizar como mínimo el historial del negocio y la experiencia de los Receptores realizando actividades relacionadas al Proyecto. Asimismo, se deberá considerar en la evaluación la viabilidad financiera del Proyecto. (4) La Sociedad Administradora tendrá la facultad de publicar Proyectos cuyos Receptores no tengan historial crediticio, siempre que su calificación de nivel de riesgo refleje esta situación de acuerdo con la metodología adoptada. (5) Dentro del proceso de evaluación de Proyectos, se debe considerar si el Receptor se encuentra en proceso de solicitud de otras alternativas de financiamiento. (...)" 
ciedad Administradora a contingencias como esa. Por otro lado, es más difícil justificar una reducción de la carga regulatoria sobre las Sociedades Administradoras si por el otro lado se les está atribuyendo una mayor responsabilidad.

¿Significa que el regulador debe quedarse de brazos cruzados? No. El regulador sí tiene un rol que cumplir en lo que respecta a la evaluación que hacen las Sociedades Administradoras sobre los Receptores y sus proyectos, y se trata de garantizar la transparencia. No existe ninguna necesidad de obligar a las Sociedades Administradoras a realizar due diligence o clasificaciones de riesgo, pero sí resulta conveniente para el desarrollo del sector que la norma exija transparencia de manera que los inversionistas sepan si las Sociedades Administradoras hacen o no hacen un due diligence, y si optan por clasificar los proyectos, que se revelen en base a qué criterios lo hacen.

Trazando el límite del regulador en la promoción de la transparencia considero que se le dará suficiente espacio al mercado para que, de manera natural, fije su propio estándar, uno que funcione y sea acorde a las condiciones del mercado. Lo que se observa en otros países es que hay Sociedades Administradoras que no hacen due diligence y otras que sí lo hacen y lo publicitan para diferenciarse del resto $y$ generar mayor atracción hacia su plataforma. Asimismo, hay compañías que hacen un mejor due diligence que otras, y hay compañías que se especializan en hacer due diligence y que son subcontratadas por las Sociedades Administradoras -e.g. Crowdcheck en Estados Unidos-. Las Sociedades Administradoras más exitosas en efecto evalúan con rigurosidad a los Receptores y sus proyectos, y justamente es gracias a ello que han sido exitosas. Considero que lo mismo debería suceder en el caso peruano sin necesidad de que la normativa o el regulador deban entrometerse más allá de garantizar un adecuado nivel de transparencia.

Si al final la normativa que se apruebe mantiene la obligación de clasificar el riesgo de los Receptores y Proyectos, creo que al menos se debería aclarar que esos servicios, si bien los presta la
Sociedad Administradora, pueden ser subcontratados a terceros que sean especialistas en ello para que las Sociedades Administradoras puedan abaratar sus costos y ser más eficientes. El Proyecto de Reglamento no establece una prohibición expresa, sin embargo, para evitar cualquier clase de interpretación en contrario, debería tratarse el tema de manera expresa.

\section{LÍMITES DE RECAUDACIÓN A RECEPTORES}

No solo las reglas que regirán el actuar de las Sociedades Administradoras serán fundamentales para el éxito o fracaso del Crowdfunding financiero en el Perú. El límite de recaudación para los Receptores es igual de importante pues influirá directamente en la demanda por parte de los Receptores de este mecanismo de financiamiento.

En la legislación comparada, lo usual es que la ley establezca un límite máximo a la cantidad de dinero que puede ser recaudado por los Receptores en campañas de Crowdfunding financiero. De manera que era de esperar que el Proyecto de Reglamento propusiera una serie de límites. Creo que son dos las razones que pueden motivar el establecimiento de límites de recaudación.

La primera razón es, en teoría, la reducción del riesgo sistémico. La lógica es que entre menos recursos se concentren en una sola campaña, menores serán las repercusiones para la economía en general si el negocio de la compañía que promovió esa campaña fracasa y los inversionistas pierden su dinero. Sin embargo, creo que pasarán muchos años para que el Crowdfunding se convierta en un sector suficientemente grande para generar un riesgo sistémico, por lo que por ahora solamente cabría hablar del límite de recaudación como una manera para que el fracaso de los Receptores repercuta en la menor cantidad de personas posibles.

La segunda justificación que encuentro, más pragmática y convincente que la primera, es que el límite permite segmentar el Crowdfunding financiero de tal manera que sea empleado por aquellas compañías para cuyo beneficio está originalmente pensado, es decir, las MYPES 
y emprendimientos de alto impacto. De esta manera se previene que empresas más grandes que tienen otras alternativas de financiamiento ingresen al sector para aprovechar sus beneficios y compitan por el financiamiento que deberían recibir aquellas.

Es por la razón descrita en el párrafo anterior que creo que tiene sentido establecer un límite de recaudación. Sin embargo, fijar el límite es un asunto delicado y en el que considero peor equivocarse por establecer un límite muy bajo que uno muy alto. Si el límite es demasiado bajo, el sector no podrá desarrollarse pues no habrá demanda suficiente.

La Ley de Crowdfunding, en su artículo 32, facultó a la SMV para establecer los límites de recaudación. Es así que el artículo 32 del Proyecto de Reglamento, en sus numerales 1 y 2, estableció los siguientes límites máximos:

"32.2 Con dicho fin, la Sociedad Administradora debe tener presente los siguientes límites máximos:

1. Por monto del Proyecto: Los Proyectos personales no podrán superar las cincuenta (50) UIT y su plazo máximo de financiamiento no deberá exceder los tres (03) años. Los Proyectos empresariales no podrán superar las doscientos cincuenta (250) UIT.

2. Por monto recibido por el Receptor: Cada Receptor no podrá recibir un monto mayor como FPF de cien (100) UIT en el caso de personas naturales y de quinientas (500) UIT en el caso de personas jurídicas, siendo posible solicitar sucesivas rondas de FPF, cuyo monto total no debe superar dichos límites en el lapso de los doce (12) meses anteriores."

Considerando que la Unidad Impositiva Tributaria - UIT para el año 2021 asciende a S/ 4,400.00, entonces, el límite máximo por ronda de financiamiento ascendería a S/ 1,100,000.00 y el límite en un plazo de 12 meses -en sucesivas rondas-ascendería a S/ 2,200,000.00.

En mi opinión, los límites propuestos son demasiado bajos. Quizás para algunas empresas que se dedican al Crowdfunding basado en préstamos funcione, pues lo usual es que los financiamientos bajo esa modalidad sean de menor cuantía y dedicados a capital de trabajo, pero creo que definitivamente no funciona para la modalidad basada en la emisión de valores o en el caso de una compañía que esté buscando un préstamo de mayor cuantía a una mejor tasa que la ofrecida en el sistema financiero.

Asimismo, debemos recordar que el Crowdfunding financiero también está pensado para financiar emprendimientos de alto impacto, los cuales tienen el potencial de crecer a gran velocidad y escala, por lo que pueden necesitar mayor cantidad de fondos. Inclusive cuando estos emprendimientos ya han pasado por algunas rondas de financiamiento y tienen otras alternativas sobre la mesa, no se les debe cerrar las puertas para optar por el Crowdfunding financiero como opción. El Crowdfunding no se trata solamente de obtener el dinero. La campaña es en sí misma una herramienta de marketing muy potente que puede ayudar a fidelizar clientes y expandir el negocio. Por eso hay compañías que, pudiendo optar por otras fuentes de financiamiento, deciden hacer nuevas rondas de Crowdfunding financiero. Mantener a ese tipo de compañías en el sector me parecería muy productivo para su promoción y desarrollo, pero no volverán si los límites son muy bajos.

Los límites propuestos son bajos inclusive si nos comparamos con otras jurisdicciones. En Estados Unidos, por ejemplo, - tras aumentar el monto original- el límite asciende a USD $1,070,000.00$, mientras que en Europa - bajo el Reglamento UE 2017/1129 - se estableció un valor máximo de EUR $8,000,000.00$, el mismo que fue adoptado, por ejemplo, por Alemania ${ }^{12}$, sin perjuicio de que las legislaciones nacionales

12. Therese Thorris "Germany raises the Equity Crowdfunding Limit to $€ 8$ million", Crowdfund Insider, 29 de junio de 2018, https://www.crowdfundinsider.com/2018/06/135692-germany-raises-the-equity-crowdfunding-limit-to-e8-million/ 
de cada país pueden establecer máximos menores. Ambos valores aplican para un periodo de 12 meses.

$Y$ no tenemos que irnos a otro continente. En el caso de Colombia, en septiembre de 2020, se tuvo que emitir el Decreto $\mathrm{N}^{\circ} 1235^{13}$ para elevar los límites inicialmente propuestos para incentivar el uso del Crowdfunding financiero. Los montos máximos inicialmente ascendían - dependiendo de si solamente participaban inversionistas no calificados o no- a 3,000 o 10,000 salarios mínimos mensuales -aproximadamente USD 794,961 y USD 2,679,870 respectivamente-, y fueron ampliados a los nuevos límites de 19,000 y 58,000 salarios mínimos mensuales -aproximadamente USD $5,034,615.00$ y USD $15,368,827.00-$. Si Colombia ya cometió el error de iniciar con límites demasiado bajos y tuvo que rectificarse, ¿por qué Perú debe esperar a darse cuenta de lo mismo en lugar de aprender de los errores de los países vecinos?

Para terminar esta sección, también quiero resaltar una limitación relevante que se ha impuesto en el artículo 40 del Proyecto de Reglamento. Este artículo establece que "El Proyecto debe ser desarrollado íntegramente en el territorio de la República del Perú." Pareciera que, lo que se busca garantizar es que los recursos recaudados no sean llevados al extranjero, sino que se queden en el Perú y que los beneficios derivados de dicha inversión se materialicen en el Perú. Sin embargo, esto me parece un gran error de la legislación. Bajo esta norma, los Receptores no podrían, por ejemplo, recaudar fondos con la finalidad de expandir sus operaciones a otros países. Y no solo a los Receptores se les cierra una alternativa de financiamiento importante, sino que si lo vemos desde la posición de los propios inversionistas, pierden una oportunidad de inversión en una empresa que, siendo exitosa localmente, tiene planes de expansión al extranjero. Nuevamente nos encontramos con una regla que, en lugar de atraer proyectos, los ahuyenta.

\section{CONCLUSIONES}

El Crowdfunding financiero es una actividad que favorecerá al financiamiento de emprendimientos de alto impacto y MYPES que hoy en día tienen dificultades para acceder al financiamiento que necesitan. Por las razones expuestas en el presente artículo, no considero que aprobar una regulación especial sea estrictamente necesario para que esta actividad se desarrolle en el Perú. Inclusive sin regulación, ya venían operando algunas plataformas de Crowdfunding bajo la modalidad de préstamos sin mayores inconvenientes. Sin embargo, en un negocio que depende tanto de la confianza que los Receptores y Sociedades Administradoras pueden generar en el público, crear una regulación especial que permita supervisar esta actividad y dar ciertas garantías adicionales podría, a la larga, resultar un factor que contribuya a un crecimiento que respete los intereses de todos los involucrados.

A lo largo de este artículo, se han identificado algunos problemas con el contenido de la Ley de Crowdfunding y su respectivo Proyecto de Reglamento que me llevan a concluir que no contribuirán al desarrollo del Crowdfunding financiero. Por el contrario, las exigencias que se imponen, principalmente a las Sociedades Administradoras, son demasiado exigentes e inflexibles, siendo las principales fallas identificadas las siguientes:

a) No diferenciar entre Sociedades Administradoras que manejan fondos del público y aquellas que no. Lo recomendable $-y$ lógico- sería reducir la carga regulatoria de éstos últimos y así generar incentivos para que las Sociedades Administradoras ideen formas más seguras de administrar el dinero de los inversionistas, por ejemplo, valiéndose de terceros.

b) No diferenciar la carga regulatoria en base al volumen de las operaciones de cada Sociedad Administradora, flexibilidad que considero necesaria para mantener las ba- 
rreras de entrada al mercado bajas. Bajo el esquema propuesto en el Proyecto de Reglamento, sin importar el volumen de operaciones, todas las Sociedades Administradoras tienen los mismos requisitos de capital mínimo y patrimonio neto, y las mismas obligaciones informativas.

c) Obligar a las Sociedades Administradoras a calificar el riesgo de los proyectos publicados en sus plataformas. Esto genera un costo adicional e incrementa su exposición en términos de responsabilidad civil y, quizás, hasta administrativa, sin un beneficio claro que lo justifique.

Asimismo, considero un error establecer que los proyectos deban desarrollarse exclusivamente en el Perú y el límite de recaudación contenido en el Proyecto de Reglamento. Un límite tan bajo como el propuesto reducirá la demanda de Receptores que podrían financiarse a través del Crowdfunding financiero. Si bien se está pensando en beneficiar a las MYPES, es necesario recordar que también se busca favorecer a los emprendimientos de alto impacto $y$, en general, cualquier empresa pequeña que tenga planes de crecimiento. La idea es que el Crowdfunding financiero pueda ser un mecanismo de financiamiento recurrente, lo que significa que el límite de recaudación debe considerar las necesidades de financiamiento de las empresas en etapas más tardías de su desarrollo y no solamente pensar en su etapa inicial o en necesidades de capital de trabajo.

Hay otros temas que considero cuestionables de la Ley de Crowdfunding y su Proyecto de Reglamento y que no han podido ser abordados en este artículo. Desde el tratamiento de las plataformas de Crowdfunding extranjeras, pasando por algunos requisitos problemáticos para el otorgamiento de las autorizaciones de organización de funcionamiento de Sociedades Administradoras, plazos que aparentan ser cortos pero que no se cumplirán en la práctica, prohibiciones absurdas como aquella que impide a las Sociedades Administradoras invertir en los proyectos promocionados en sus plataformas, terminando en la imposición de límites de inversión que responden a una visión paternalista del Estado.

La Ley de Crowdfunding delegó en la Superintendencia del Mercado de Valores la tarea de supervisar y reglamentar la actividad de Crowdfunding financiero. Sin embargo, mi lectura del Proyecto de Reglamento, es que se está cometiendo el error de siempre. Pareciera que cada vez que se pretende regular una actividad nueva, las normas formuladas se terminan llenando de limitaciones y regulaciones inflexibles bajo la excusa de proteger a los inversionistas, siempre aplicando el mismo molde de normas; como si el mercado debiera funcionar de la manera ideal que el funcionario público de turno se imagina o nada.

Quizás sea el momento de hacer un cambio y confiar un poco más en el mercado. Tal vez no dejarlo a sus anchas, pero sí guiarlo sin que ello implique imponerle un esquema rígido. No puedo garantizar que los incentivos analizados en este artículo funcionen a la perfección y que el mercado quede libre de abusos o actos fraudulentos. Lo cierto es que, con o sin regulación, el fraude es y será un riesgo en todos los mercados, por lo que no tiene sentido ahogar al mercado en regulación excesiva en un afán de minimizar al máximo ese riesgo. En el caso particular del Crowdfunding financiero, si las cosas no salen como se espera bajo una regulación más flexible, al menos habremos cometido un error nuevo y aprenderemos de él, y no el error de siempre, del cual parece hemos aprendido poco. 